
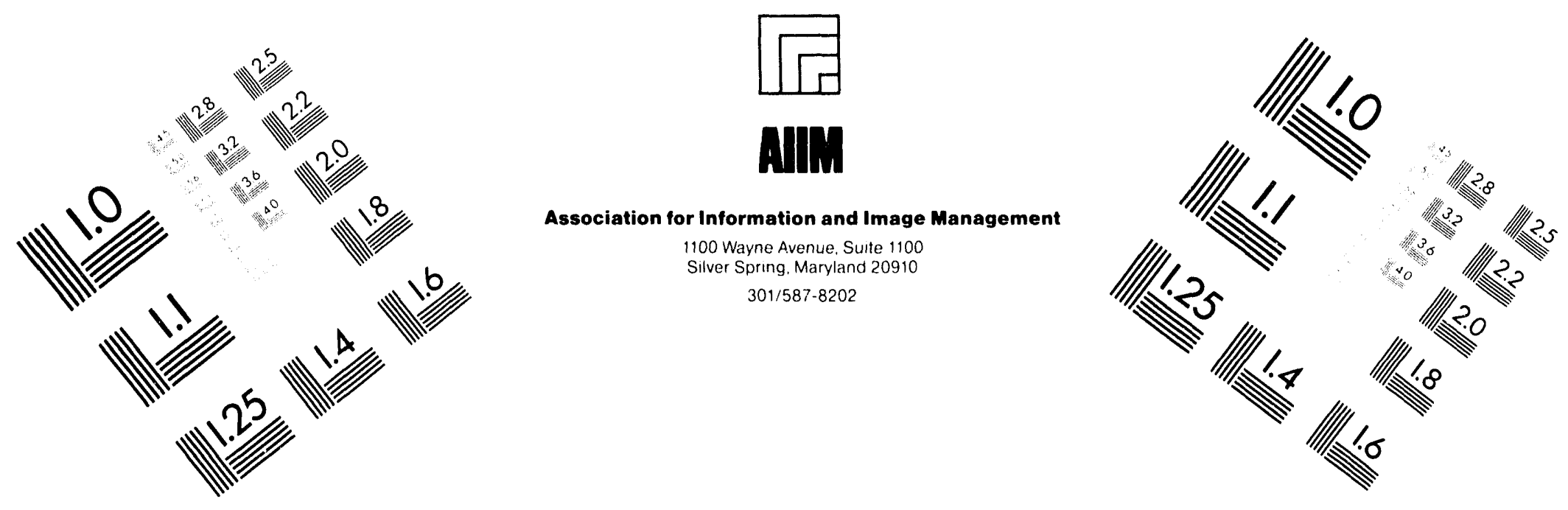

\title{
Centimeter
}

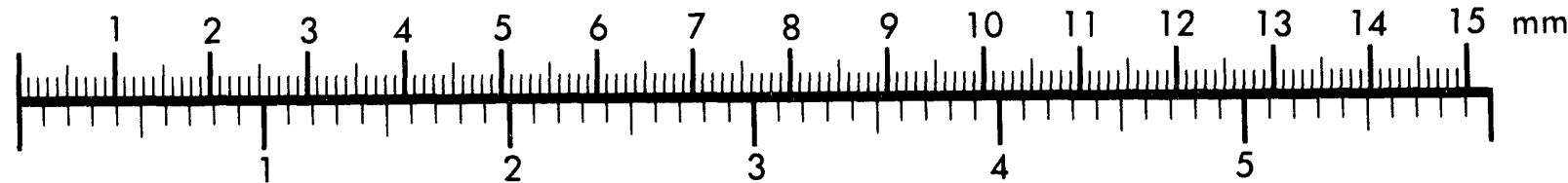
Inches
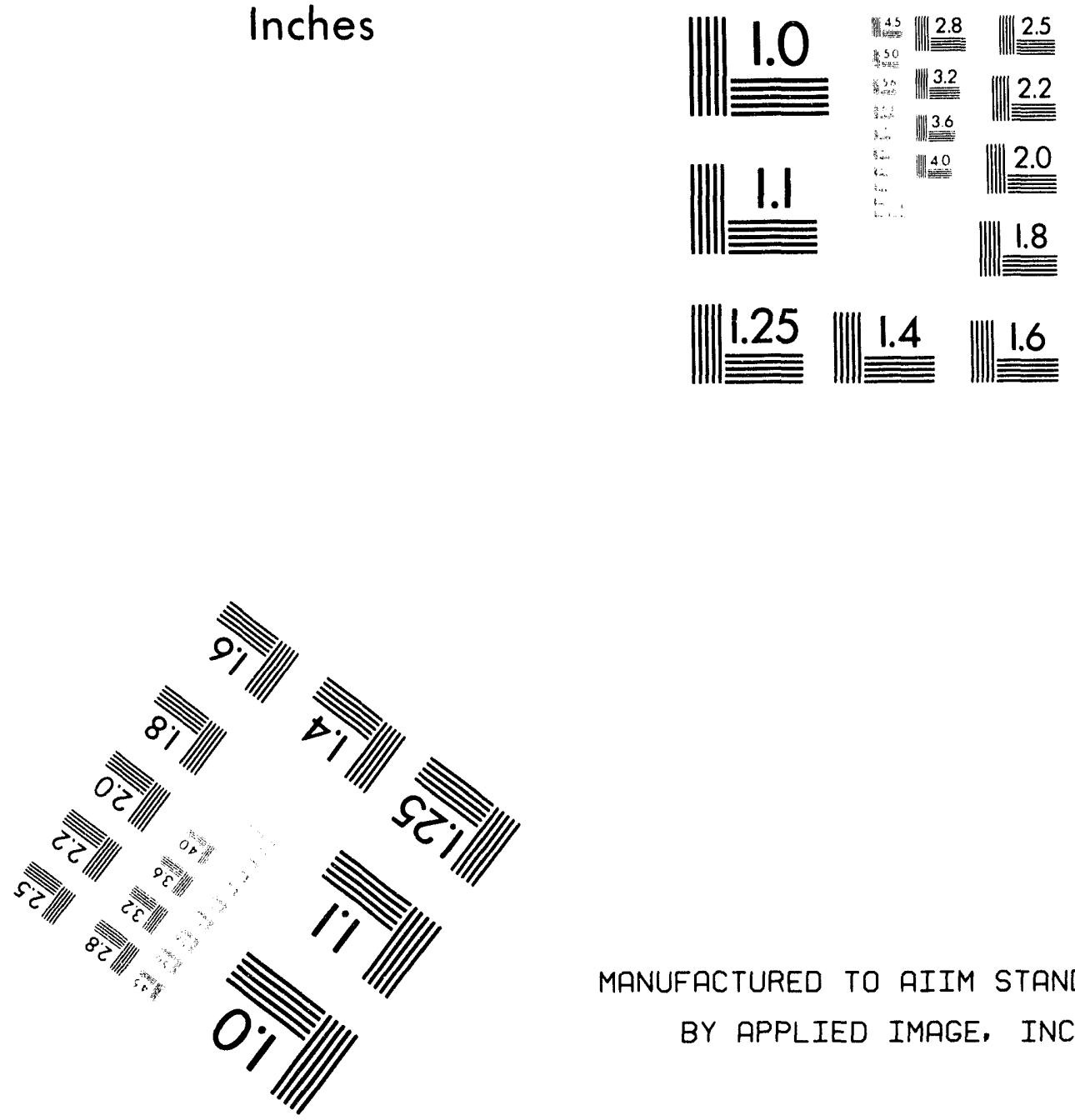

MANUFACTURED TO AIIM STANDARDS

BY APPLIED IMAGE, INC.

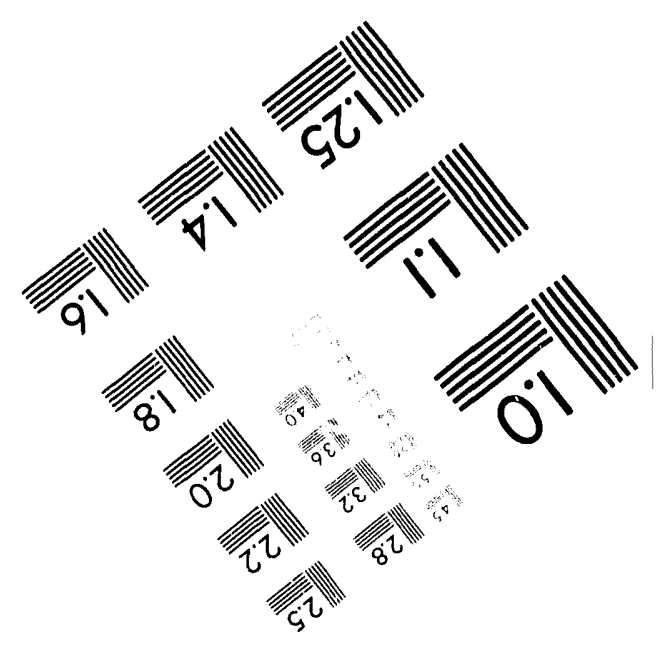



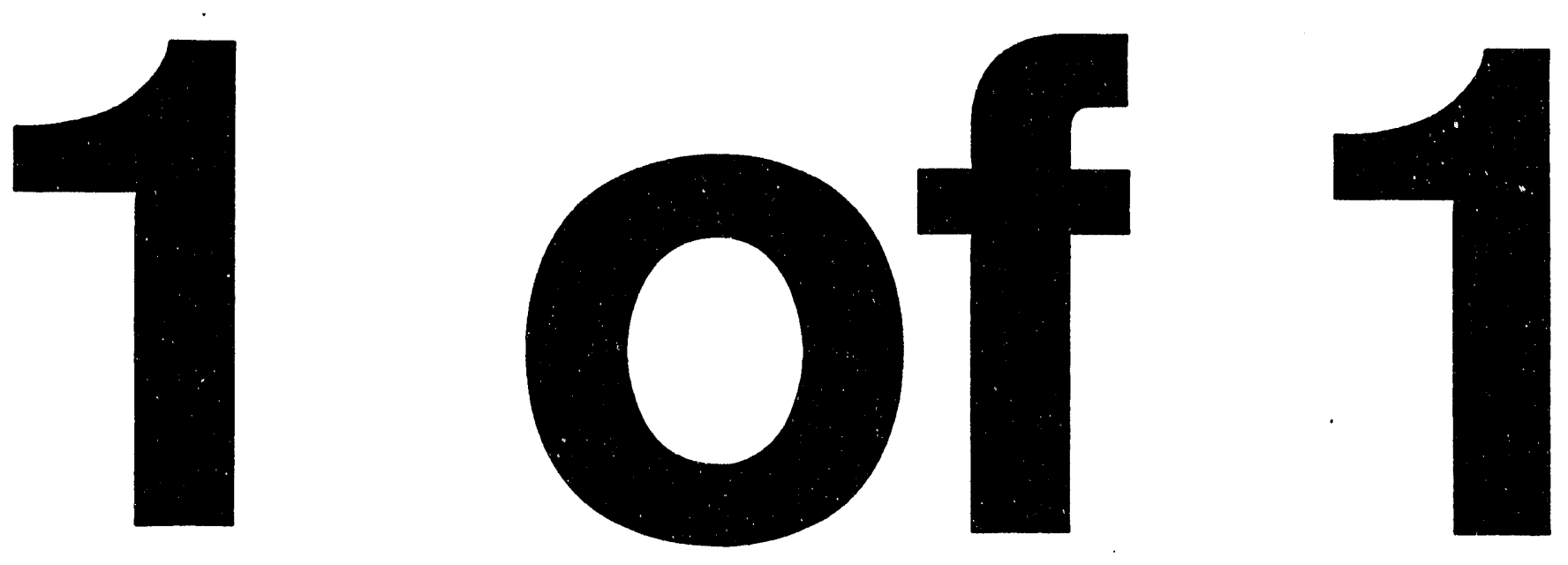


\title{
Conf $-940664--2$
}

UCRL-JC-115748

PREPRINT

\section{The Logic Behind Thick, Liquid-Walled, Fusion Concepts}

\author{
Ralph W. Moir
}

This paper was prepared for submittal to the Thind International Symposium on Nuclear Technology University of California, Los Angeles, California June 27-July 1, 1994

April 15, 1994

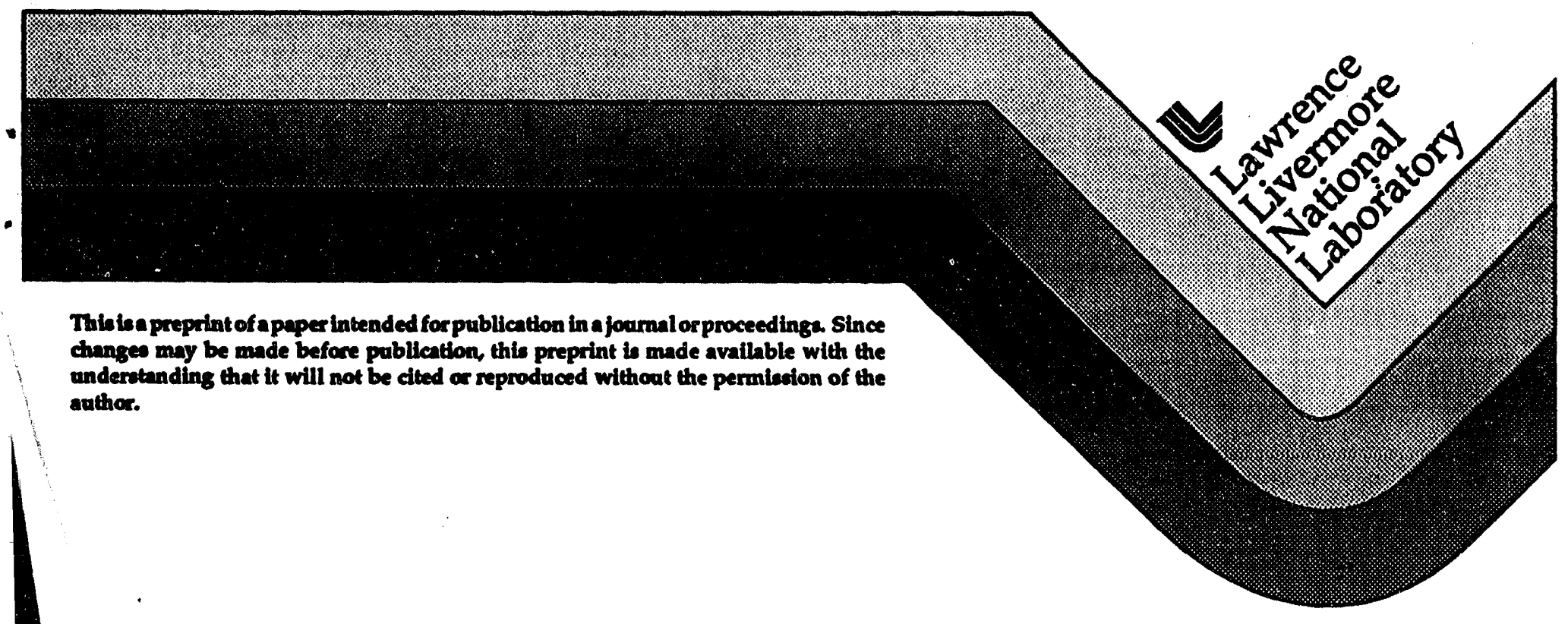


This document was prepared $\approx m$ scconnt of work spomsored by an agency of the Uniled States Governmeat. Neither the United States Governenest nor the Ubil verdity of Cellfornila nor sany of their employees, makes any warrenty, express or imaplied, or

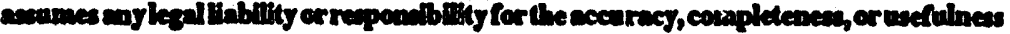

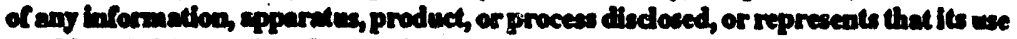

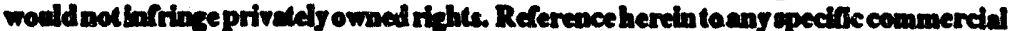

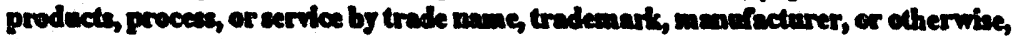

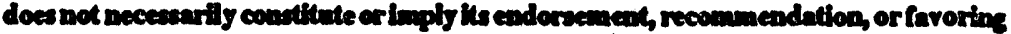
by the United States Goremment or the Undrectity of Collifornia. The views and opinions of authors exprewed hereln do not neceasarily atale or refect those of the United States Government or the University of Californian and shall not be used for advertising or product endorsenent parposes. 
The Logic Behind Thick, Liquid-Walled, Fusion Concepts*

Ralph W. Moir

Lawrence Livermore National Laboratory, P. O. Box 808, L-637, Livermore, California 94551

Submitted to Third International Symposium on Fusion Nuclear Technology, June 27-July 1, 1994, University of California, Los Angeles. 


\begin{abstract}
It may be possible to surround the region where fusion reactions are taking place with a neutronically thick liquid blanket which has penetrations that allow only a few tenths of a percent of the neutrons to leak out. Even these neutrons can be attenuated by adding an accurately placed liquid or solid near the target to shadowshield the beam ports from line-of-sight neutrons. The logic of such designs are discussed and their evolution is described with examples applied to both magnetic and inertial fusion (HYLIFE-II). These designs with liquid protection are self healing when exposed to pulsed loading and have a number of advantages over the usual designs with solid first walls. For example, the liquid-protected solid components will last the life of the plant, and therefore the capacity factor is estimated to be approximately $10 \%$ higher than for the non-liquid-walled blankets, because no blanket replacement shutdowns are required. The component replacement, operations, and maintenance costs might be half the usual value because no blanket change-out costs or accompanying facilities are required. These combined savings might lower the cost of electricity by $20 \%$. Nuclear-grade construction should not be needed, largely because the liquid attenuates neutrons and results in less activation of materials. Upon decommissioning, the reactor materials should qualify for disposal by shallow burial even when constructed of ordinary 304 stainless steel. The need for a high-intensity $14-\mathrm{MeV}$ neutron test facility to develop first-wall materials is avoided or greatly reduced, saving billions of development dollars. Flowing molten $\mathrm{Li}$, the molten salt Flibe $\left(\mathrm{Li}_{2} \mathrm{BeF}_{4}\right)$, and molten $\mathrm{Li}_{17} \mathrm{~Pb}_{83}$ have been considered. An advantage of molten salt is that it will not burn and has a low tritium solubility and therefore low tritium inventory.
\end{abstract}

\title{
1. Introduction
}

En route to practical fusion, among the many problems that need solution is how to cope with the highly energetic $14-\mathrm{MeV}$ neutrons that are expected to seriously damage the first-wall materials. The idea we examine here is the use of a liquid wall facing the fusion region, thick enough to slow down and stop a large portion of the neutrons before they can damage the solid structural material behind 
the liquid layer. The use of a thick liquid wall has a number of benefits that have not been adequately appreciated and that may both ease the development of fusion energy and also make the end product so much more desirable as to speed up its development. This short paper is not intended to be an exhaustive review of liquid walled concepts, but rather a discussion of some recent work. Earlier work is reviewed in Monsler et al. [1].

\section{Lifetime of structural walls with liquid protection}

The lifetime of structural steel has been calculated[2] for a simplified geometry of a point neutron source and a shell of varying thickness for two lithiumcontaining liquids that have low vapor pressure (densities below $1013 / \mathrm{cm}^{3}$ ) at temperatures of interest to thermal power conversion systems. These liquids are Flibe (a molten salt, $\mathrm{Li}_{2} \mathrm{BeF}_{4}$ ) and lithium. The results are plotted in Fig. 1 for 100 dpa (displacements per atom) for austenitic steel. For a thickness of $0.5 \mathrm{~m}$ of Flibe or $1.6 \mathrm{~m}$ of lithium, the structural material will last for 30 years before its structural properties are seriously degraded. The third liquid that has a sufficient lithium content to be considered for fusion (neutrons reacting with $\mathrm{Li}$ produce the fusion fuel, tritium) is a mixture of lithium and lead. Neutron damage will be different for different examples but can be approximately scaled. For example, the reduction in damage scales approximately exponentially with liquid thickness and inversely with the square of distance to the structural material. This approximation assumes linear curves that are reasonably valid for Fig. 1 . Thus, if the distance is doubled, the damage would diminish by a factor of 4 . If the neutron damage to the wall is reduced by a factor of 100 for a given thickness of liquid, then doubling that thickness would produce a 10,000 or $100^{2}$ reduction of the damage.

\section{Decommissioning of stainless steel structural walls by shallow burial}

Requiring that structural materials at decommissioning time qualify for shallow land burial is one way to determine the acceptable levels of activation, rather than requiring the more expensive deep geologic disposal required of fission wastes. The shallow burial requirement applies the concept of the "intruder dose." The burial site is assumed to be guarded for 100 years. After 500 years, intruders are assumed to dig up the site and live their whole lives there. If they stand next to a large block of waste material, they will get what is called the whole-life (70-year) 
intruder dose. This is to be compared to the "acceptable" lifetime dose of radiation, which is taken as $5 \mathrm{mSv} / \mathrm{y}(0.5 \mathrm{rem} / \mathrm{y})$, typical of the background dose from natural causes. This intruder dose has been calculated[3] for various thicknesses of liquid and is plotted (for Flibe) in Fig. 2. We can see that for thicknesses greater than $0.8 \mathrm{~m}$ of Flibe the intruder dose is adequately low for 304 stainless steel; therefore this steel would qualify for shallow land burial upon decommissioning. The $\mathrm{Nb}$ and $\mathrm{Mo}$ that are absent in 304 stainless steel but present in 316 stainless steel add about 2 orders of magnitude to activation and therefore to the intruder dose. An additional $0.7 \mathrm{~m}$ of Flibe would be needed to make 316 stainless steel qualify for shallow burial. The main reason to add Mo to stainless steel is to enhance aqueous corrosion resistance. In molten salt the main corrosion inhibitor is nickel, so we believe that 304 stainless steel should have almost as low corrosion rates as the $<2 \mu \mathrm{m} / \mathrm{y}$ of 316 stainless steel in the presence of flowing Flibe[4].

\section{Inertial fusion example of liquid wall protection}

HYLIFE-II is the name of an inertial fusion power plant design concept [2] that uses a thick liquid-wall and that is shown in several views in Fig. 3. Oscillating deflectors cause the liquid jet flows to form a pocket that surrounds the microexplosions. The jets are formed in static nozzles that convert liquid pressure into kinetic energy of flowing liquid at nil pressure. The jets are oscillated back and forth by deflectors. The joint between the nozzle and deflector does not need a seal because of the lack of pressure. For more details see Palmer [5]. Heavy-ion beams are focused onto a target to initiate a microexplosion six times a second. The yield is 350 MJ, or 100,000 times smaller than the earliest fission bombs. The liquid serves to cushion the shock and blast effects to easily manageable levels and to slow and capture the neutrons, so that the solid materials are predicted to last the life of the plant.

The flowing nature of the liquid is sufficient to carry the heat produced to the power plant, where it is converted into electricity. The flow also serves to clear the chamber for the next shot $1 / 6$ of a second later (as discussed below in greater detail.)

The dramatically higher wall loading illustrates the effectiveness of liquid wall protection. For the HYLIFE-II example with a wall at $3 \mathrm{~m}$, the power flux carried by fusion's energetic 14-MeV neutrons towards the wall is $15 \mathrm{MW} / \mathrm{m}^{2}$ compared to $2.7 \mathrm{MW} / \mathrm{m}^{2}$ in some tokamak magnetic fusion designs. In spite of the 6-times- 
higher neutron flux, the wall lasts 30 years because the liquid strongly reduces the neutron damage. Table 1 summarizes these parameters.

Solid first-walled fusion concepts are envisioned to have to shut down every few years to change out the damaged blanket structures surrounding the fusion reaction region and to replace these structures with new ones. Not having to shut down means the plant capacity factor will be higher; some estimates[2] suggest it might rise from $75 \%$ to $85 \%$, with a corresponding $12 \%$ reduction in the cost of electricity.

Without a protective liquid jet array the blanket structures would become highly radioactive and would need special handling machines and special storage rooms to receive them before they can be prepared and transported to a waste disposal site. By contrast, with a thick liquid wall the damage would be so minimal that the materials would require removal only upon decommissioning. The savings that would result from needing fewer blanket structures and less handling. equipment, storage space, and waste disposal would be considerable, perhaps lowering the cost of electricity by another 10 to $12 \%$. Thus, the combined savings from higher plant capacity factor and no blanket structures being changed out during the life of the plant is predicted to result in more than $20 \%$ lower cost of electricity: The improved HYLIFE-II plant is discussed by Hoffman, and the cost of electricity is estimated at 5.1 and $3.6 ₫ / \mathrm{kWh}$ at 1 and $2 \mathrm{GWe}(1990 \$)[6]$, respectively.

If we have no first wall, then an expensive materials development program will not have to be carried out, and neutron sources that would likely cost well over a billion dollars need not be constructed for inertial fusion. Some people have claimed the materials development for fusion might be as expensive and take as long as the development of the fusion process itself. Many billions of dollars have been estimated for this decades-long job. The use of a thick liquid wall is predicted largely to do away with the need for this first-wall materials development program.

Another advantage of reduced activation due to the thick liquid layer would be that the consequence of any accident or abnormal event might be so much less as not to harm the public; therefore, the construction could be of ordinary industrial grade rather than of the much more rigorous and expensive nuclear grade, the so called "N-Stamp" certification construction standard. With liquid protection, ordinary 304 stainless steel is predicted to qualify, eliminating the need for new materials. This would save costs and improve the public's perception of fusion power, reassuring the public that even if there is an accident, anyone beyond the site boundary would not be harmed. 
One problem area is that about $0.2 \%$ of the $14-\mathrm{MeV}$ neutrons escape up the heavy-ion beam ports. The thick jets of liquid shown in Fig. 3, are assumed to come within $10 \mathrm{~mm}$ of the heavy-ion beams that are $70 \mathrm{~mm}$ in diameter. This results in a holes in the liquid jet array through which the 14- $\mathrm{MeV}$ neutrons can escape. These escaping 14-MeV neutrons form "square" beamlets that are $90 \mathrm{~mm}$ on a side and are centered on each ion beamlets. By accurately injecting a liquid or frozen liquid close to the target (inside the dashed region shown in Fig. 3e) it may be possible to attenuate by an order of magnitude or more even those $(0.2 \%)$ neutrons, while still allowing the beams to strike the proper place on the target. A specific heavy ion target design (similar to Fig. 3e), has beams aimed at radiators located $23 \mathrm{~mm}$ apart with the capsule in between. This separation from the beam aim point and the source of neutrons in principle permits placing a solid or liquid material to attenuate neutrons that would otherwise pass up the beam ports. The benefit of such an "attenuator" would be greatly reduced radiation in the region of the heavyion beam-focusing magnets. The challenge would be to locate a solid or liquid jet within $3 \mathrm{~mm}$ of the edge of the heavy-ion beam path. A jet would fall vertically about 2 meters, as shown in Fig. 4.

The liquid configuration for a proposed neutron attenuator is shown in Fig. 4. Calculations show that $0.2 \%$ of the neutrons produced in the fusion reaction pass uncollided up the 12 beam ports without the attenuator. The attenuator shown in Fig. 4 is a $300 \mathrm{~mm}$ wide ribbon-shaped jet of liquid tapered in thickness from about $12 \mathrm{~mm}$ nearest the target to $33 \mathrm{~mm}$ thick farthest away. The minimum path length of neutrons as shown is $160 \mathrm{~mm}$, giving an attenuation factor of 9 (the 14-MeV mean free path is $71.8 \mathrm{~mm}$ ). The maximum path length is $300 \mathrm{~mm}$, giving an attenuation factor of 67 . This extra shielding of the beam ports will be helpful in extending the lifetime of the final focus magnets. The attenuator casts a "neutron shadow" on the beam ports, as illustrated by a sample calculation shown in Fig. 5 . Fig. 5 demonstrates that the neutron fluence is decreased by two orders of magnitude at the beam port by a one-dimensional neutron transport calculation. Three-dimensional neutron transport calculations should be made to refine the calculations on the attenuator idea and to predict magnet lifetime.

5. Chamber clearing of liquid and vapor 
The incoming liquid clears droplets from the prior shot, as shown in Fig. 6. For the example of $6 \mathrm{~Hz}$ shot repetition rate, the incoming liquid traveling at $12 \mathrm{~m} / \mathrm{s}$ sweeps the region clear during its $2-\mathrm{m}$ travel. The incoming liquid is not perturbed by the prior shot because it is contained within the oscillating nozzle deflectors. While it remains to be demonstrated experimentally, we can with some confidence predict that the central chamber will be clear of droplets that otherwise might interfere with passage of the heavy ions to the target. The edges of the nozzles must themselves not create droplets that might subsequently find themselves within the beam paths. However, a small percentage of the beam can be lost to droplets without decreasing the yield significantly.

Any droplets left over from the prior shot that are in the beam's path but outside of the oscillating flow region can be cleared by vapor blow-off and gravity. The venting vapor from the prior shot will travel up the beam lines and might sufficiently entrain any droplets in the beam line. The vapor would carry these droplets either into the shutter or into an angular bend of the beam line where the droplets are eliminated by continuing in a straight line. Only the droplets traveling more than $1000 \mathrm{~m} / \mathrm{s}$ get through the shutter before it closes in $1 \mathrm{~ms}$. In that case, the droplets exceeding $1000 \mathrm{~m} / \mathrm{s}$ reach the small angular bend in the beam tube and will be diverted and therefore they will be out of the beam path before the next beam pulse comes through. Gravity can be quite effective at droplet clearing at lower pulse rates. At $2 \mathrm{~m}$ distance, $\mathrm{a} \pm 1^{\circ}$ beam has a width of $70 \mathrm{~mm}$. A droplet starting at rest would drop $137 \mathrm{~mm}$ during the interpulse time at $6 \mathrm{~Hz}$. If its upward velocity was the worst possible, it would rise and then fall a distance of only $43 \mathrm{~mm}$ at $6 \mathrm{~Hz}$, i.e. still in the beam path. If we could lower the pulse rate to $4.2 \mathrm{~Hz}$, the worst droplet would just clear the $70 \mathrm{~mm}$ beam path.

\section{Magnetic fusion example of liquid wall protection}

In inertial fusion the fusion reactions are over by the time the pulse of evaporated material arrives. The interpulse time is enough to condense the vapor, bringing the density down low enough for the beams to propagate to the target for the next shot. By contrast, in magnetic fusion a way must be found to prevent contamination and cooling of the burning plasma from vaporization of the liquid. A liquid-walled concept was suggested for one magnetic fusion concept by N. C. Christofilos[7] in 1970 (published posthumously in 1989). The problem of adapting liquid wall protection to a tokamak has been discussed in the literature[8], along 
with a discussion of a concept called LINUS[9] for a long, thin, reversed-field configuration. A Spheromak-like [10] configuration could possibly use liquid wall protection, as illustrated in Fig. 7. The structural walls shown by heavy lines are assumed to rotate about the vertical axis at about 2 revolutions per second. This keeps the injected liquid centrifuged against the wall as shown. The advantage of this configuration is that the fast-moving liquid, with residence time of about $0.3 \mathrm{~s}$, can remove considerable radiative surface heat flux. As an example, we assume 2100 MW of fusion power with $10 \%$ radiating to the surface at $3 \mathrm{~m}$ distance $\left(0.9 \mathrm{MW} / \mathrm{m}^{2}\right)$. This will give a surface temperature rise of about 120 and $590 \mathrm{~K}$ for $\mathrm{Li}$ and Flibe, respectively, using the equations and data in Ref. [7]. Evaporative cooling of the liquid will limit the temperature rise with Flibe to about half the value above but will have little effect on the lithium case. Additionally, at about $200 \mathrm{~K}$ temperature rise in Flibe, collisionality in the evaporating vapor will limit the evaporation rate.

It remains to be shown if the evaporation due to this surface heat flux will excessively cool and contaminate the burning plasma. Liquid lithium would be advantageous because of its high thermal conductivity. However, the problem of MHD effects caused by liquid lithium motion across magnetic fields will have to be considered. This problem is lessened with Flibe because of its low electrical conductivity. The information in Fig. 7 is illustrative only, and many modifications can and need to be made. For example, the opening at the top can be increased, and the radial annular space can be completely closed off. The magnetic configuration must be made with induced currents in the plasma region and by coils placed outside of the liquid. If the first wall is at $3 \mathrm{~m}$, so the damage and activation calculations shown in Fig. 1 and 2 are directly applicable for the same power of 1000 MWe. The methods developed to study the plasma/gas boundary in tokamaks could be applied to the problem here.

\section{Disadvantages of liquid wall protection}

There are some known disadvantages of liquid-walled fusion concepts. In the case of inertial fusion, the evaporated liquid must condense quickly enough in order not limit the $\mu$ ulse rate by interfering with the passage of the beams to the target. Another concern is that splashed liquid from a prior microexplosion must not interfere with the passage of the beams to the target. In the case of magnetic fusion, splashed liquid and evaporation could excessively contaminate the plasma. It remains to be demonstrated if liquid configurations can be created repeatedly with 
little enough splash. The moving parts that create the liquid configuration must themselves be reliable so as not to degrade the advantage of using liquid protection. The amount of liquid required and the pumping power can become significant. In the example of Ref. [2], the cost of the liquid and its pumping power contribute about $9 \%$ of the cost of electricity, a substantial but acceptable amount considering that some pumping and heat-transfer liquids are needed in any fusion power plant. When neutrons are absorbed in most any material activation results. In Flibe the activity of $18 \mathrm{~F}$ is $300 \mathrm{MCi}$. Its short half-life of $2 \mathrm{hr}$ and its nonvolatile nature result in a favorable safety assessment[2]. It remains to be shown by laboratory demonstrations if liquid configurations can be made to meet the conditions discussed above and thereby achieve the stated advantages.

\section{Summary}

The concept of a thick liquid surrounding the fusion reaction region promises to give advantages to fusion that could lower its cost of electricity by an important $20 \%$, lower its development cost by billions of dollars by easing the materials development problem, and make the environmental and safety advantages of fusion even greater. With these potential advantages, there is considerable incentive to invest research funds into the liquid-walled concept to see if the claims are as advantageous as they appear, because these advantages could have such an important consequence on fusion's development. 


\section{References}

[1] Monsler et al.. An Overview of Inertial Fusion Reactors Designs," Nuclear Technol./Fusion 1, (1971) 302- ????.

[2] R. W. Moir et al.. HYLIFE-II: A Molten Salt Inertial Fusion Energy Power Plant Design-Final Report, Fusion Technol. 25 (1994) 5-25.

[3] J. D. Lee. Waste Disposal of HYLIFE-II Structure, Issues and Assessment, Lawrence Livermore National Laboratory, Livermore, CA, UCRL-ID-111589 (1992), to be published in Fusion Technol.

[4] J. R. Keiser, J. H. DeVan, and E. J. Lawrence. Compatibility of Molten Salts with Type 316 Stainless Steel and Lithium, J. Nucl. Mat 85 and 86 (1979) 295 .

[5] P. A. House. HYLIFE-II Reactor Chamber Design Refinements, submitted to 11th Topical Meeting on the Technology of Fusion Energy, June 19-23, 1994, New Orleans.

[6] M. A. Hoffman and Y. T. Lee. Impact of Improvements in HYLIFE-II on Safety, Performance and Cost," These proceedings.

[7] N. C. Christofilos, Design of a High Power-Density Astron Reactor, J. Fusion Energy 8, (1989) 97-105.

[8] R. W. Moir. Rotating Liquid Blanket with No First Wall, Fusion Technol. 15 (1989) 674-679 .

[9] A. E. Robson. The LINUS Concept in Unconventional Approaches to Fusion, ed.

B. Brunelli and G. G. Leotta (Plenum, New York, 1982).

[10] R. L. Hagenson and R. A. Krakowski. The Spheromak as a Compact Fusion Reactor, Los Alamos National Laboratory Report LA-010908-MS (1987). 


\section{ACKNOWLEDGMENTS.}

Discussions with Darwin Ho on target design, Tom Dolan on allowable doses, Palmer House on jet design, Jeff Latkowski on neutron attenuation calculations and Ron Petzoldt on rotating liquid flow and figure plotting are gratefully acknowledged. This work was performed under the auspices of the U.S. Department of Energy by Lawrence Livermore National Laboratory under contract W-7405-Eng48. 


\section{Captions}

Fig. 1. Structural material lifetime versus thickness of the liquid protecting the structural material for 304 and 316 stainless steel. The lifetime is measured by the term that materials people call "displacements per atom," taken as $100 \mathrm{dpa}$ for an austenitic steel such as 304 stainless steel.

Fig. 2. Intruder lifetime dose versus thickness of the liquid protecting the structural material. If the intruder dose is less than $5 \mathrm{mSv} / \mathrm{y}$ or $0.5 \mathrm{rem} / \mathrm{y}$, the material qualifies for shallow land burial.

Fig. 3. Several views of a recent inertial fusion example of a thick liquid-walled fusion chamber protection concept called HYLIFE-II: (a) The chamber shown with the pumps that circulate the protecting liquid , (b) an artist's view, showing the set of crossed jets of liquid that protect the beam port and the liquid that forms a pocket around the microexplosion, (c) front view with the crossed jets of liquid removed showing the liquid pocket, (d) cross section at the target elevation (aerial view), showing the open space for vapor venting and $0.5 \mathrm{~m}$ of liquid to attenuate neutrons in all directions except the beam paths, and (e) the heavy-ion target.

Fig. 4. Cross section of HYLIFE-II chamber showing a $30-\mathrm{cm}$ neutron attenuator to shield the beam ports from line-of-sight neutrons. The enlarged view of the target shows the attenuator and the region of shadow shielding. The liquid jet attenuator is flowing down between all six beam pairs.

Fig. 5. The neutron fluence versus angle behind the attenuator illustrates the shadow shielding effect of the attenuator. The fluence $14-\mathrm{MeV}$ neutrons at the beam ports $\left( \pm 1^{\circ}\right)$ is reduced by 2 orders of magnitude.

Fig. 6. The liquid from the oscillating nozzle deflectors is shown at different times to illustrate the effect of sweeping the chamber clear of droplets and placing liquid between the shot point and the end of the deflectors for their own protection. The 2$\mathrm{m}$-long deflectors move through $\pm 1.55^{\circ}$ or $\pm 54 \mathrm{~mm}$. Notice that there is a possibility of injecting targets downward between the deflectors.

Fig. 7. Liquid protection concept for a Spheromak configuration. The inlet speed is $10 \mathrm{~m} / \mathrm{s}$ in the plane and an average of $12 \mathrm{~m} / \mathrm{s}$ perpendicular to the plane. The 
rotation rate about the vertical axis is approximately 2 revolution per second. The flow rate is $235 \mathrm{~m}^{3} / \mathrm{s}$ with a pumping power of $34 \mathrm{MW}$ (assuming $50 \%$ of jet pumping power is recovered).

Table 1.

Wall lifetime related parameters for an inertial fusion example with liquid protection and a magnetic fusion example without such protection.

$\begin{array}{lll}\begin{array}{l}\text { Wall load (flux), } \\ \text { MW/m² }\end{array} & \begin{array}{l}\text { HYLIFE-II } \\ 15^{*}\end{array} & \begin{array}{l}\text { ARIES-IV }^{*} \\ 2.7\end{array} \\ \begin{array}{l}\text { Wall dose (fluence), } \\ \text { MW.y/m² }\end{array} & 380^{*} & 13 \\ \text { Wall life, y } & 30 & 6.5 \\ \text { damage, dpa } & 100 & 200 \\ \text { wall material } & 304 \text { SS } & \text { Va } \\ \text { * without liquid } & & \\ + \text { dpa is displacements per atom } & \\ \text { ** Source: F. Najmabadi, R. W. Conn et al., The ARIES-I Tokamak Reactor Study, Final Report, UCLA-PPG-1323 } \\ \text { Vol. 1 (1991). }\end{array}$




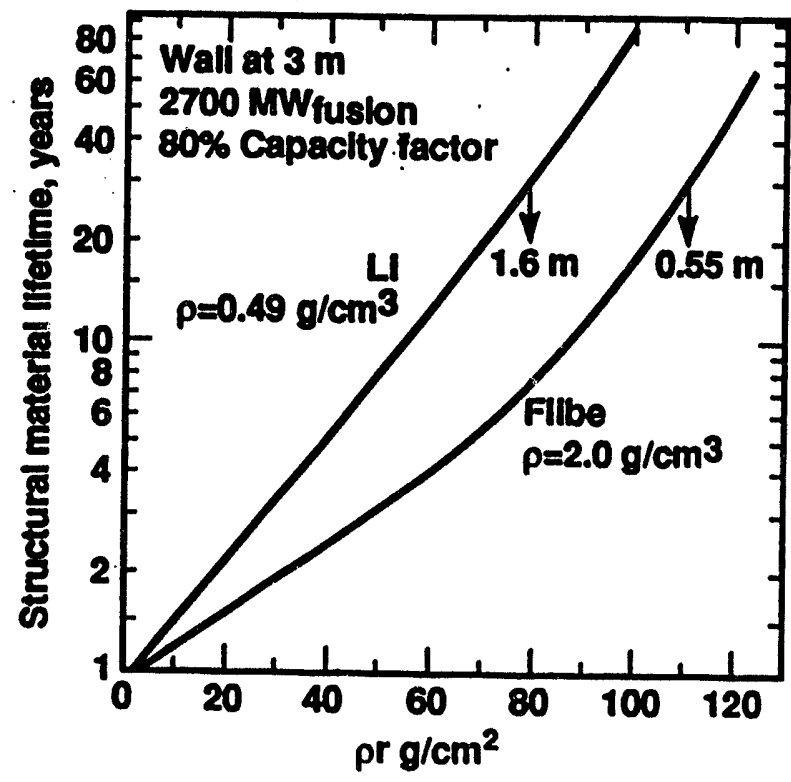




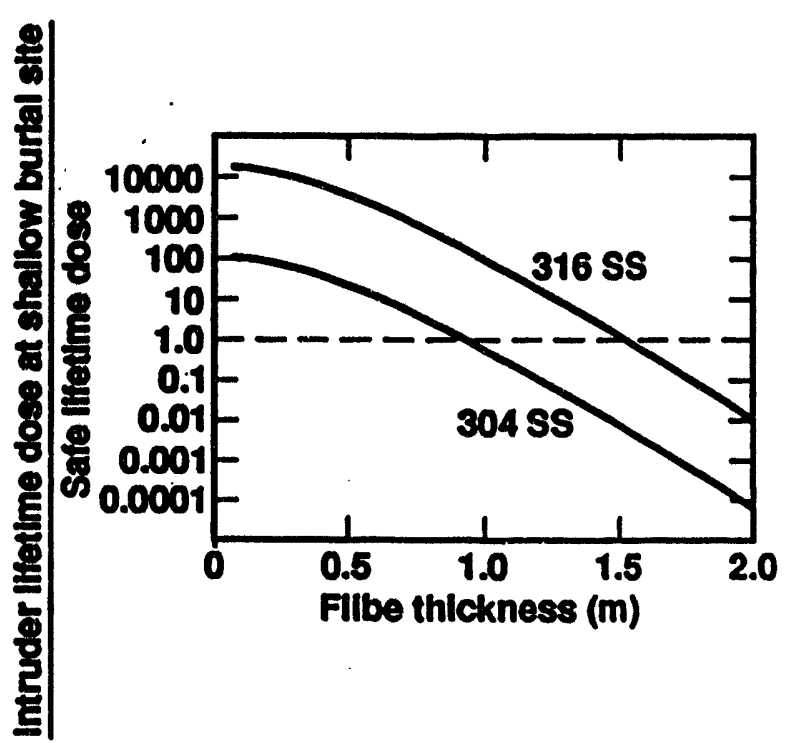

FIGURE 2

MFE-IFE-rm-0094-36

R. Moir 


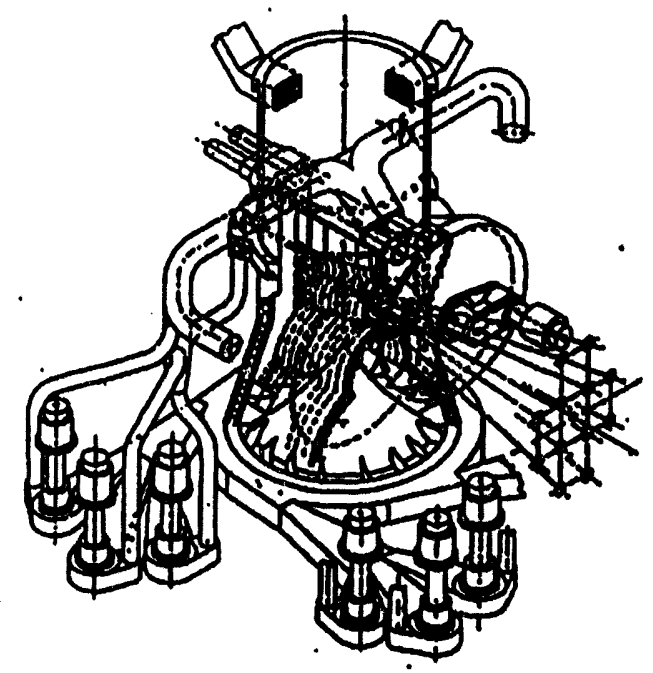

(a)
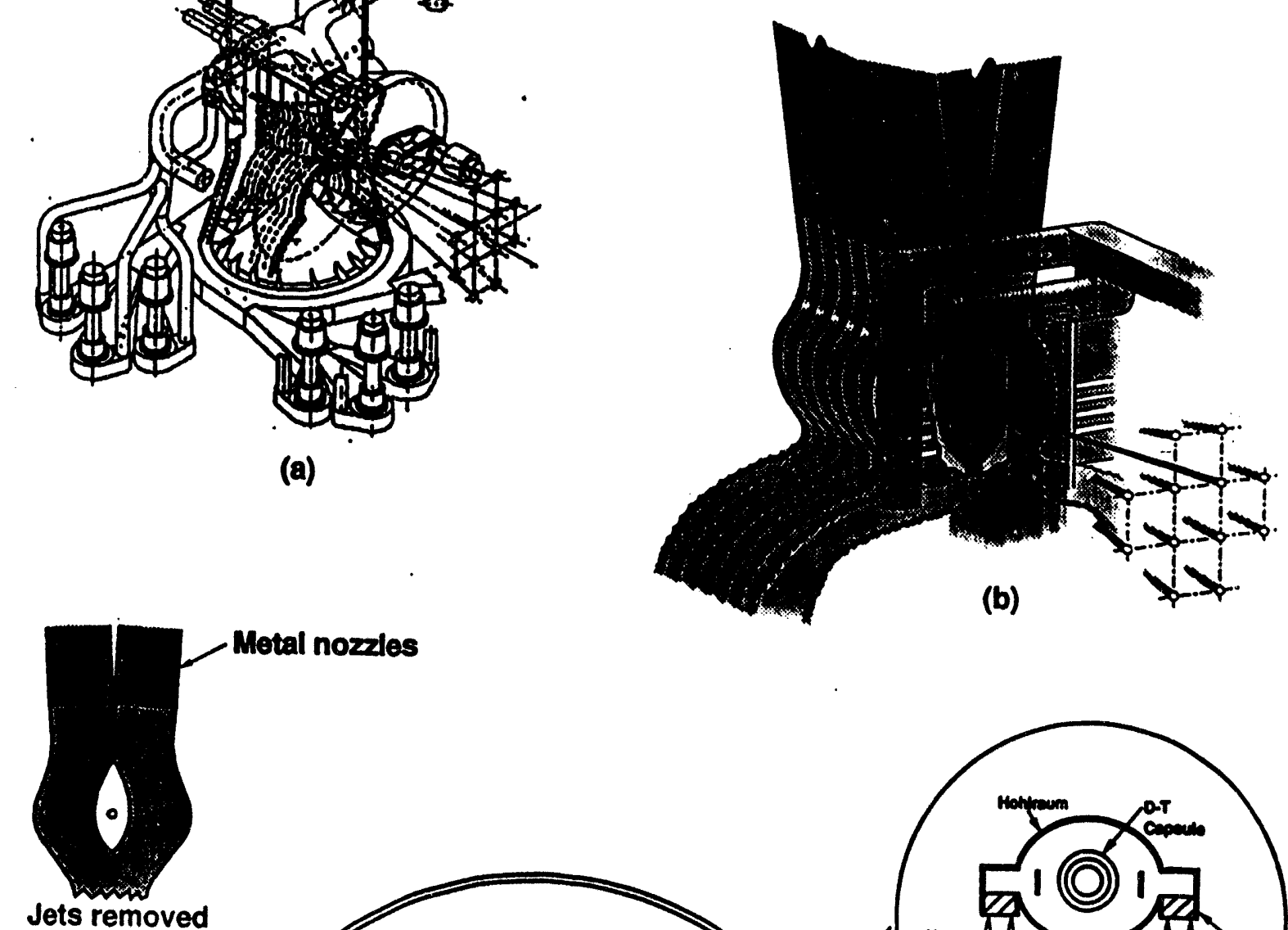
Metal nozzles Front View

(c)

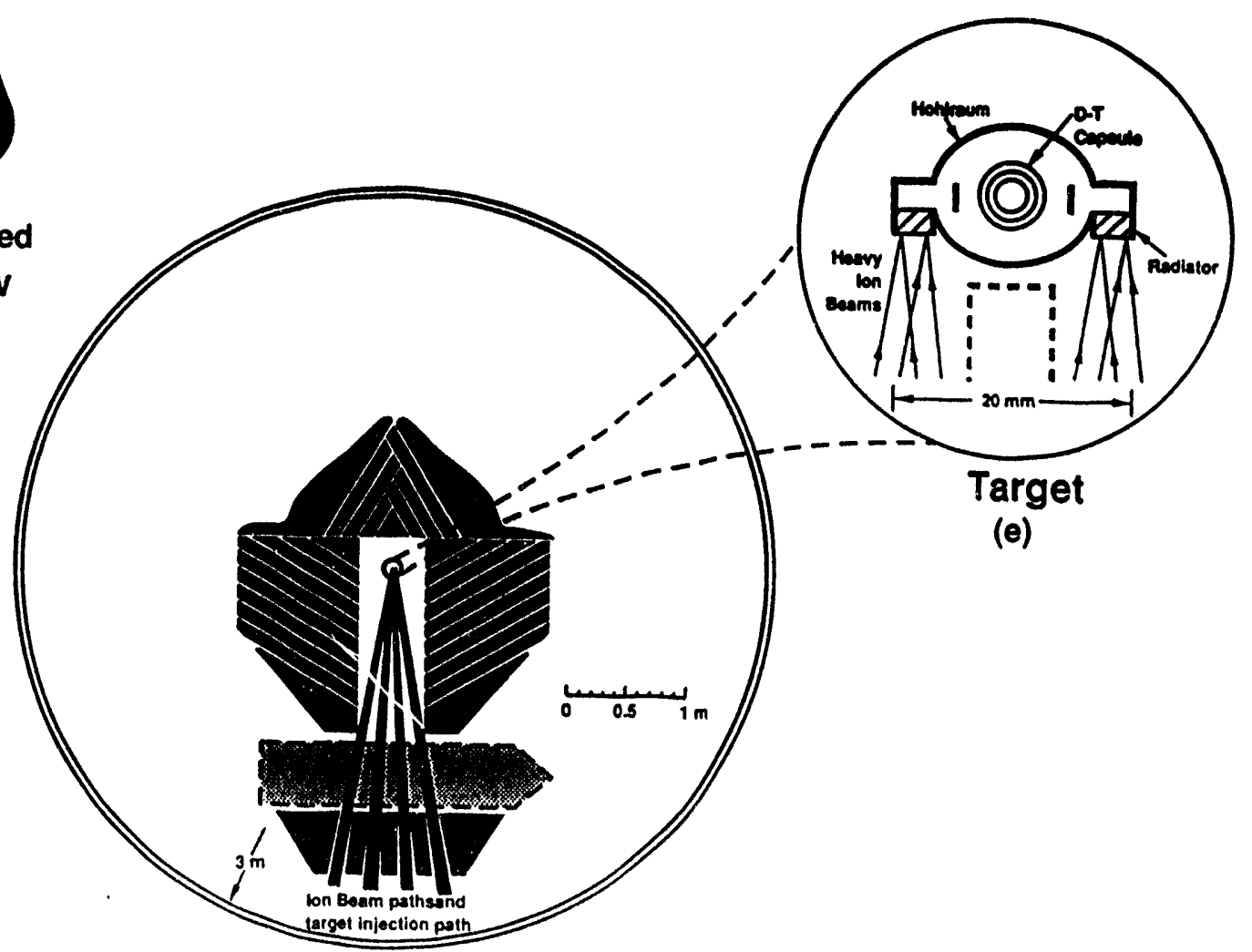

Cross Section through liquid Top View

(d) 


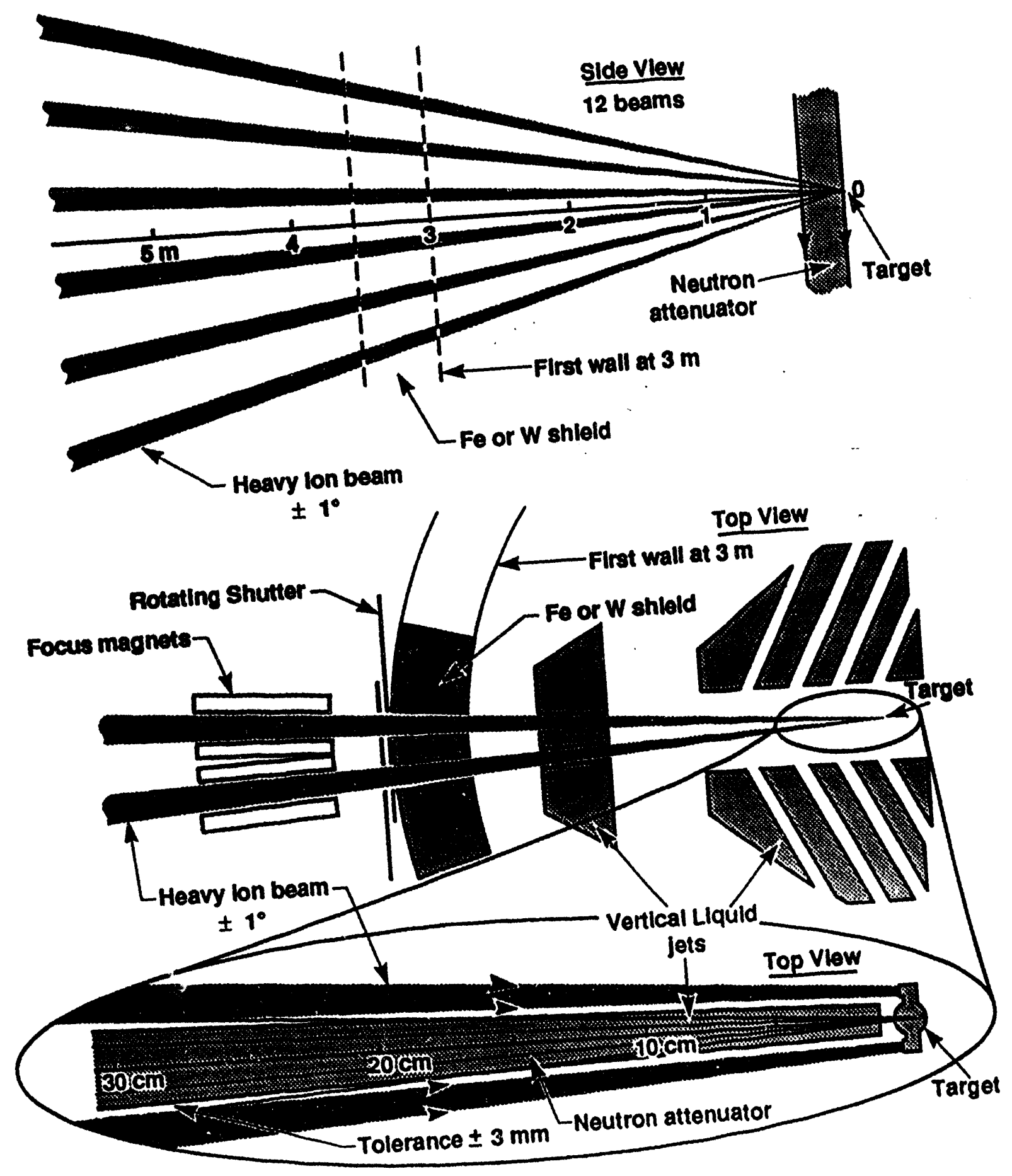

FIGURE 4

MFE-AFE-TM-0404-5

R. Moir 

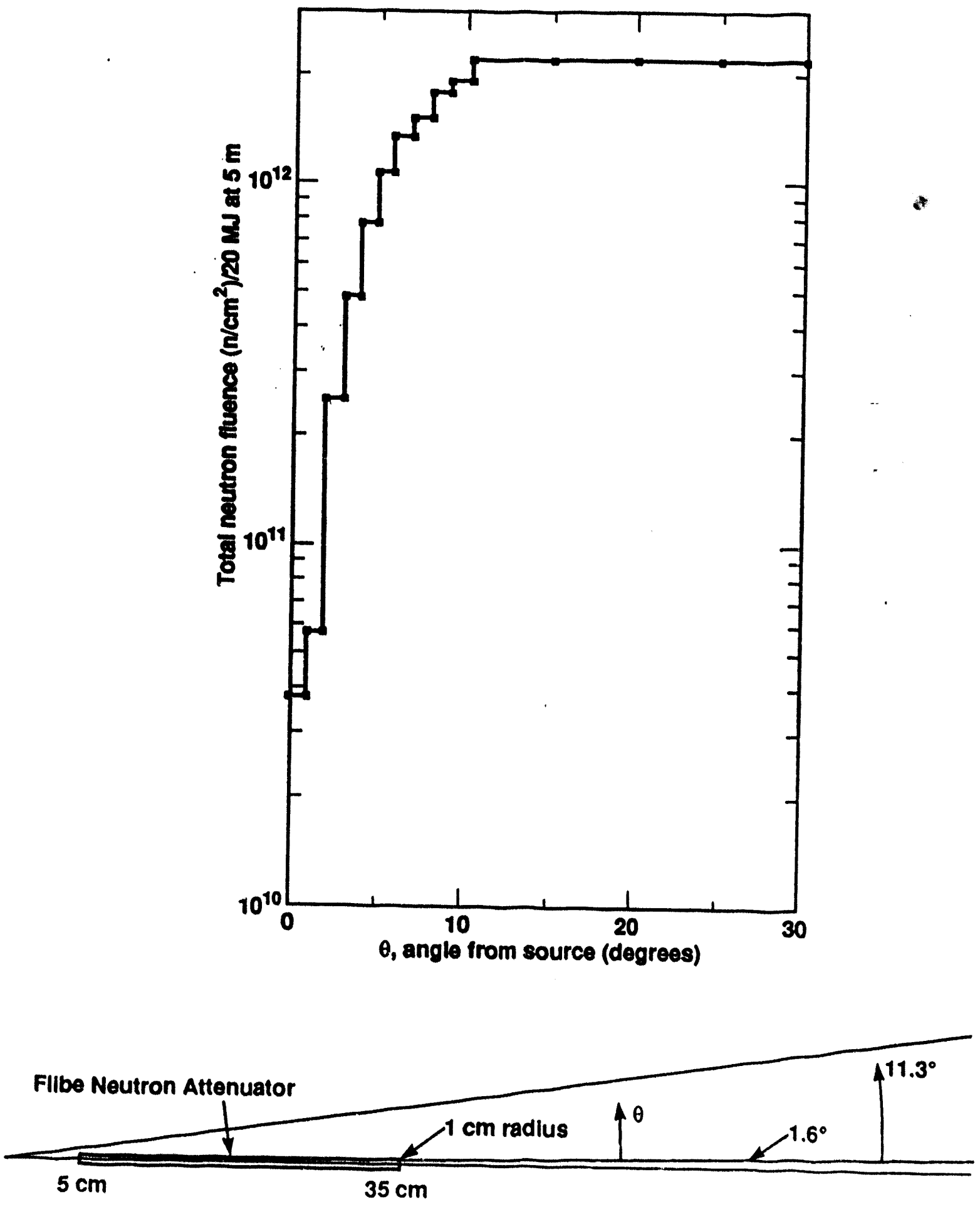

MFE AFE-TM OMQS

FIGURE 5

R. Moir 


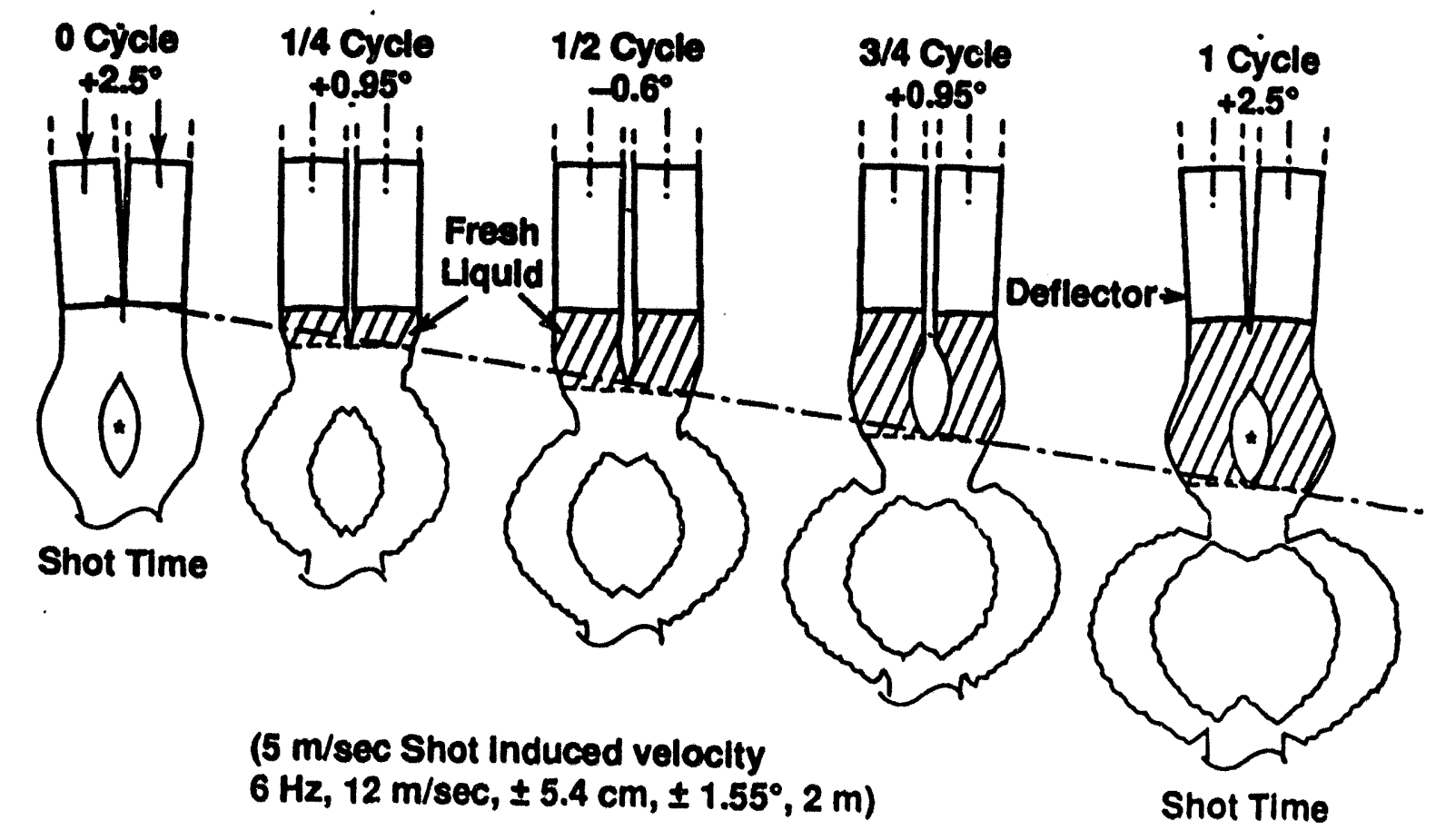

MFE-ICF-rm-0394-1

FIGURE 6

R. Moir 


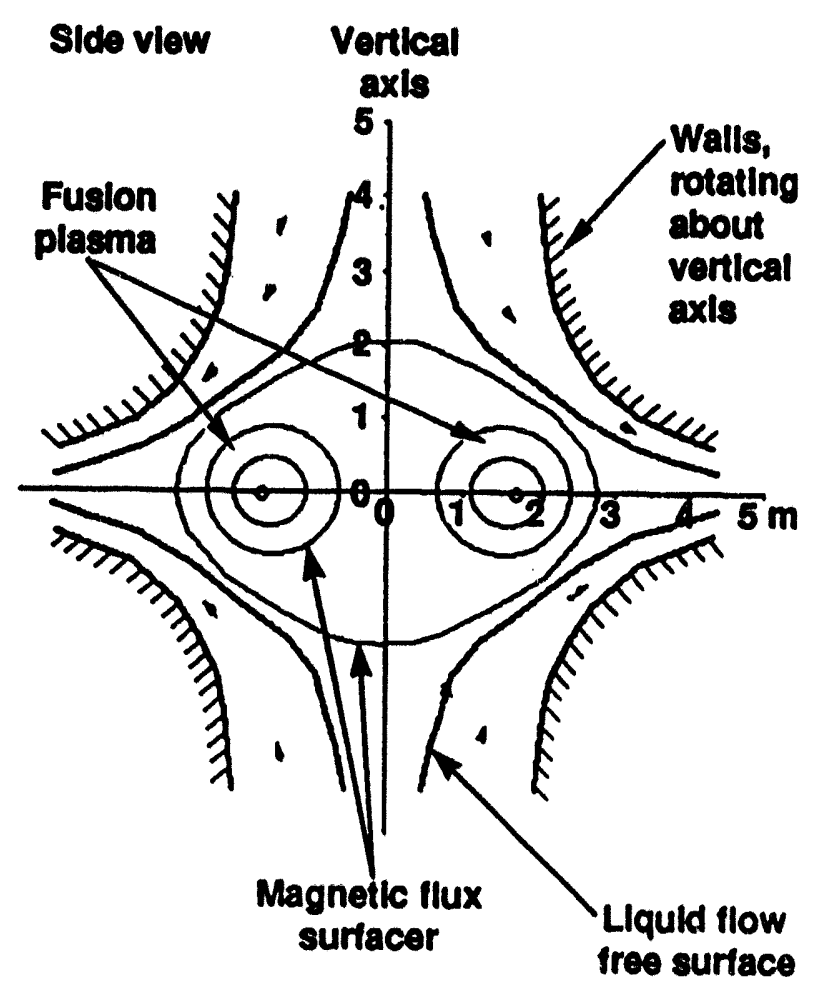



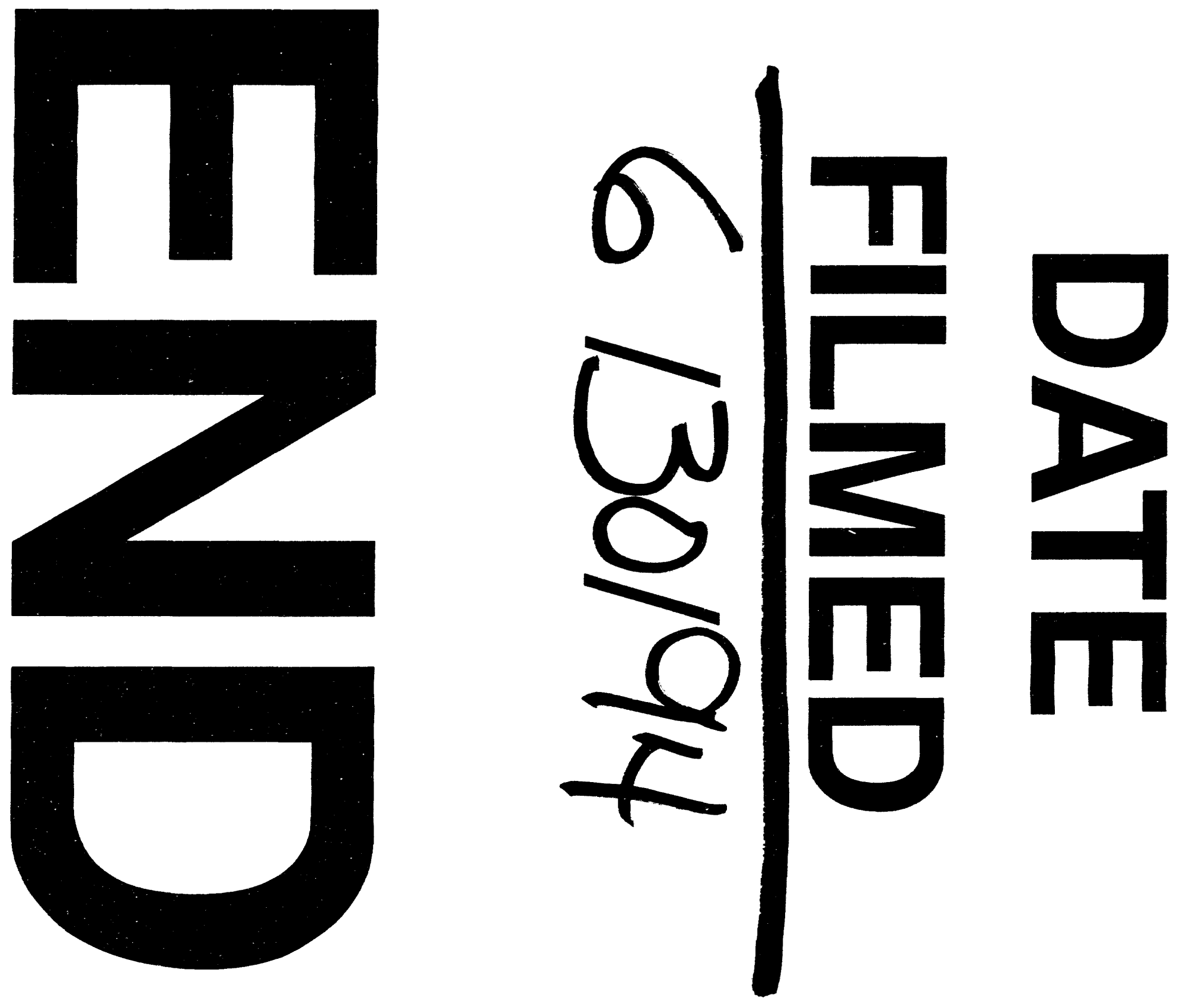
